\title{
Stability Study Interpretation Terminology
}

National Cancer Institute

\section{Source}

National Cancer Institute. Stability Study Interpretation Terminology. NCI Thesaurus.

Code C96078.

Terminology developed to support Study Interpretations within the Stability Data Standards. 